\title{
Susceptibilidade à invasão das Unidades de Conservação federais por espécies exóticas invasoras da flora terrestre
}

\author{
Aina de Carvalho França ${ }^{*}$, Rafaela Guimarães Silva ${ }^{2}$, Eraldo Aparecido Trondoli Matricardi', \\ Alexandre Bonesso Sampaio², Tainah Corrêa Seabra Guimarães ${ }^{2}$
}

\begin{abstract}
RESUMO: Este estudo teve como objetivo avaliar a susceptibilidade das Unidades de Conservação federais à invasão por espécies exóticas invasoras da flora terrestre. Para tanto, foram selecionadas 8 variáveis a fim de saber a influência das variáveis de uso e cobertura da terra no aumento de riqueza de espécies invasoras da flora terrestre em 283 UCs federais em todo o Brasil. Para a análise foram utilizados modelos lineares generalizados (GLM). A inferência multimodelo permitiu obter o modelo médio a partir dos 6 melhores modelos que avalia a relação dos vetores de introdução e propagação de espécies exóticas invasoras da flora terrestre e sua sua riqueza $\left(w_{i}<0.95\right)$. Dentre eles, foi escolhido como melhor modelo aquele com o peso Akaike mais alto $\left(\mathrm{w}_{\mathrm{i}}=0.119\right)$. Os resultados deste estudo indicam que as distâncias de áreas mineradas e de cobertura de florestas são estatisticamente significativas no aumento e redução, respectivamente, da riqueza de EEI da flora terrestre nas Unidades de Conservação. Portanto, é importante a manutenção de remanescentes de vegetação nativa no entorno das UCs a fim de se evitar a invasão local e o controle de atividades relacionadas a mineração que potencialmente possam facilitar a ocorrência e propagação de EEI nas UCs.
\end{abstract}

Palavras-chave: Áreas protegidas, uso e cobertura da terra, invasões biológicas, plantas invasoras, geoprocessamento

\section{Susceptibility to the invasion of federal Conservation Units by invasive alien species of terrestrial flora}

ABSTRACT: The aim of our study was to assess the susceptibility of federal Conservation Units to the invasion of invasive alien species (IAS) of terrestrial flora. Therefore, we selected 8 variables in order to understand land use and land cover variables influence on the increase of IAS richness of terrestrial flora in 283 UCs throughout Brazil. We applied Generalized linear models (GLM) in the data analysis. Then, from the multi-model inference and 6 best models, we obtained the average model. The average model allowed us to assess the relationship between the vectors of introduction and propagation of invasive alien species of terrestrial flora and their richness $\left(\mathrm{w}_{\mathrm{i}}<0.95\right)$. The best model was chosen by the highest Akaike weight $\left(\mathrm{w}_{\mathrm{i}}=0.119\right)$. Thus, we found that the distances from mined areas and forest cover are statistically significant in increasing and reducing the EEI richness of terrestrial flora in Conservation Units, respectively. Therefore, it is important to keep remnants of native vegetation around the UCs in order or avoid biological invasion as well as control mining activities around them which could potentially facilitate the occurrence and spread of IAS in the UCs.

Keywords: Protected areas, land use and land cover, biological invasions, alien plants, geoprocessing

\section{INTRODUÇÃO}

As invasões biológicas estão entre os principais motivos de perda da biodiversidade em todo o mundo, contribuindo com a extinção de mamíferos, anfíbios, répteis, plantas, além de provocarem danos significativos no ecossistema e também danos socioeconômicos (SIGNORI, 2018).

Espécies exóticas são aquelas que se encontram fora da sua área de origem, e toda espécie exótica invasora (EEI) que consegue se estabelecer, adaptar e reproduzir de tal forma que confere a ela a capacidade de dominar habitats, competindo com espécies nativas e provocando distúrbios no ecossistema (SIGNORI, 2018). Nem toda espécie exótica torna-se invasora, pois somente algumas delas conseguem se estabelecer e ter sucesso, podendo, dessa forma, ser uma ameaça à biodiversidade (MAGALHÃES e SILVAFORSBERG, 2016). O homem, desde os primórdios, transporta espécies exóticas para longe dos seus locais de origem, seja para criação de animais, razões ambientais, alimentação, paisagismo ou outros usos econômicos, esse transporte sempre aconteceu e foi intensificado no período das grandes navegações, em 1492, com o retorno de Colombo à Europa após o descobrimento das Américas. A globalização atua como catalisador no processo de

\footnotetext{
${ }^{1}$ Universidade de Brasília

${ }^{2}$ Instituto Chico Mendes de Conservação da Biodiversidade

* Email: aina.carvalho.franca@gmail.com
} 
dispersão de exóticas invasoras, e muitas delas são utilizadas pelo homem em diversas formas de atividades, como ornamentais, alimentícias, comerciais etc, podendo provocar desequilíbrios no ecossistema (OLIVEIRA NETO et al., 2015; SAMPAIO e SCHMIDT, 2013; MAGALHÃES e SILVA-FORSBERG, 2016). Várias vias de propagação são responsáveis pela disseminação de EEI, sendo as principais relacionadas a expansão do transporte e ao alto volume do comércio, que contribuem com a propagação para além de sua origem (LATOMBE et al., 2017).

O transporte não intencional entre espécies pode ser mediado por estradas e veículos terrestres; aeródromos; portos e embarcações, entre regiões do globo. O transporte intencional ocorre, geralmente, para fins de paisagismo e ornamentação, no caso de espécies vegetais. $\mathrm{O}$ uso ornamental, juntamente com a criação de animais domésticos, corresponde a $40 \%$ de todas as introduções de espécies exóticas que ocorrem no Brasil (SAMPAIO e SCHMIDT, 2013). As plantas invasoras causam prejuízos econômicos, principalmente na agricultura, em todo o mundo. No Brasil estima-se que as perdas anuais na agricultura provocados por plantas invasoras, algas e ácaros já passa de 40 bilhões de dólares. Tal valor não leva em consideração problemas mais sérios, como os impactos ambientais, perda de biodiversidade, aumento no manejo, custo e prevenção das espécies invasoras, e impactos a saúde humana (OLIVEIRA NETO et al., 2015).

Plantas invasoras competem por água, luz, nutrientes e por alelopatia (SIMÕES, 2014), apresentam uma grande capacidade de utilização dos recursos, pois utilizam de forma eficiente os nutrientes do solo, disputam por espaço físico e provocam o sombreamento excessivo das nativas. Além disso, as EEI são resistentes aos patógenos, tolerantes ao desfolhamento e herbivoria, têm alta capacidade de regeneração, longo período de floração e frutificação, alta capacidade de propagação vegetativa, entre várias outras características que favorecem o rápido crescimento da sua população e consequentemente a redução de espécies nativas, pois a sua população tende a aumentar mais rápido devido à ausência de inimigos naturais no local (MAGALHÃES e SILVAFORSBERG, 2016).

EEI são capazes de alterar o balanço energético e o ciclo hidrológico em ecossistemas intocados, além de modificarem completamente a ciclagem de nutrientes e o regime do fogo. A invasão se intensifica ao longo dos anos, fazendo com que seja cada vez mais difícil voltar à paisagem original, pois inibe a sucessão ecológica das espécies nativas (SIGNORI, 2018).
O estudo do uso e cobertura da terra é um dos fatores que mais atuam na indicação de espécies invasoras em uma área. A influência do uso da terra na riqueza de plantas invasoras varia desde o aumento da fonte de propágulos até alteração das condições ambientais e regime de perturbação. A proximidade de áreas urbanas, que apresentam alta densidade populacional, ou até mesmo áreas agrícolas, também são mais susceptíveis a invasão e acabam contribuindo para que áreas intocadas venham a ser invadidas com o tempo (PAUCHARD e ALABACK., 2004).

Como forma de conservação e preservação dos recursos e reservas naturais estão as Unidades de Conservação (UCs). Na América do Sul, as áreas protegidas abrigam uma alta concentração de espécies endêmicas (PAUCHARD e ALABACK., 2004), entretanto, elas estão sempre vulneráveis às mudanças antrópicas. $\mathrm{O}$ uso e cobertura da terra, efeitos de borda e a fragmentação dentro ou próximo de áreas protegidas são alguns dos vários exemplos da interferência humana nesses locais, e como consequência tem-se $\mathrm{o}$ aumento da fonte de propágulos por espécies invasoras dentro das UCs, que por sua vez são uma ameaça à biodiversidade e difíceis de controla e erradicar (SPEAR et al., 2013; PAUCHARD e ALABACK., 2004).

A porcentagem de plantas exóticas em uma Unidade de Conservação está correlacionada com o número de pessoas que vistam o local (VILA e PUJADAS, 2001). Muitas plantas invasoras são fáceis de serem transportadas pelos turistas para diversos pontos turísticos, sobretudo para Unidades de Conservação. O ser humano consegue dispersar sementes para distâncias muito maiores do que as plantas conseguem dispersar com os seus mecanismos. A dispersão para locais distantes da planta mãe gera preocupações, principalmente, em relação às áreas protegidas e também em relação ao turismo sustentável, pois muitos turistas são vetores não intencionais de dispersão de sementes (PICKERING e MOUNT, 2010).

Nesse sentido, no presente estudo, buscamos entender a relação de variáveis espacialmente explícitas e a ocorrência de EEI da flora terrestre em Unidades de Conservação Federais em todo o território brasileiro (desconsiderando as Áreas de Proteção Ambiental e as UCs costeiras ou de ilhas oceânicas), com destaque às mudanças de uso e cobertura da terra no entorno das UCs. Os resultados desta pesquisa contribuem para a definição de estratégias de monitoramento e controle da ocorrência e propagação de espécies invasoras da flora terrestre em áreas protegidas no Brasil.

\section{MATERIAIS E MÉTODOS}


A área de estudo é composta por 283 Unidades de Conservação federais, desconsiderando as Áreas de Proteção Ambiental (APAs) e Unidades de Conservação em ilhas oceânicas ou costeiras. Para cada uma delas foi estimada a riqueza de espécies exóticas invasoras da flora terrestre. Os limites das Unidades de Conservação federais (julho de 2019) assim como dados de riqueza de EEI da flora terrestre (julho de 2020) foram cedidos pelo Instituto Chico Mendes de Conservação da Biodiversidade (ICMBIO).

As variáveis ambientais, ou seja, todos os vetores e vias de introdução e propagação de EEI, foram selecionados com base na literatura e objetivando compreender quais deles são mais prejudiciais para as UCs. Dentre elas, foram selecionadas densidade populacional; cobertura de floresta nativa e plantada, áreas mineradas, pastagem, agricultura; distância de áreas mineradas e distância de viveiros e jardins botânicos.

McDonald et al. (2009) verificaram que os efeitos da influência da urbanização se dão a uma distância maior ou igual a $50 \mathrm{~km}$ das áreas protegidas e que a proximidade entre as áreas protegidas e as áreas urbanas tende a aumentar a medida que se tem o crescimento populacional nos locais. Por isso, nesse estudo utilizamos um buffer igual a $50 \mathrm{~km}$, a fim de averiguar e susceptibilidade de Unidades de Conservação à invasão de espécies exóticas da flora terrestre. Nesse sentido, os dados de cobertura e densidade foram estimados considerando um buffer de $50 \mathrm{~km}$ enquanto que as variáveis de distância foram estimadas a partir dos limites das UCs.

Os dados de uso e cobertura da terra $(\%)$ e de distância de áreas mineradas (km) são do ano 2018, e foram obtidos a partir da Coleção 4.1 da plataforma MapBiomas (www.mapbiomas.org). O shapefile da variável distância de viveiros e jardins botânicos $(\mathrm{km})$ foi retirado do OpenStreetMap (ver em https://www.openstreetmap.org). Já a partir do censo demográfico revisado de 2010 do Instituto Brasileiro de Geografia e Estatística (IBGE, ver em ftp://geoftp.ibge.gov.br/organizacao_do_territorio/m alhasterritoriais/malhasmunicipais/municipio_2010// ), calculou-se a densidade populacional humana (habitantes $/ \mathrm{km}^{2}$ ).

Todos os dados e shapefiles foram processados em ambiente SIG (Sistema de Informações Geográficas) a fim de padronizar todas as informações. Para a análise estatística dos dados, utilizou-se o software R.

\section{Análise de dados}

Primeiramente, o desenho experimental do estudo considerou cada Unidade de Conservação federal e sua zona de influência de $50 \mathrm{~km}$ como uma amostra independente, mesmo que esta não seja a realidade espacial. Esta estratégia foi adotada com o objetivo de evitar a autocorrelação espacial do modelo e, portanto, seu enviesamento. Além disso, para tal também se adotou medidas de cobertura e densidade para que o efeito área de cada UC pudesse ser minimizado e, consequentemente, diminuir o ruído dos modelos estatísticos.

Para a construção do modelo global (Equação 1), primeiro passo da análise de dados, considerou-se a riqueza de EEI da flora terrestre como variável resposta ou dependente e as vias e vetores de introdução e propagação de EEI como preditoras.

$$
\begin{aligned}
& R i q=\operatorname{Cob}_{F N}+\operatorname{Cob}_{F P}+\operatorname{Cob}_{M}+\operatorname{Cob}_{A}+\operatorname{Cob}_{P}+ \\
& D_{P}+\operatorname{Dist}_{A M}+\operatorname{Dist}_{V . J B}
\end{aligned}
$$

em que: Riq: riqueza da flora terrestre; CobFN: cobertura de florestas nativas; CobFP: cobertura de florestas plantadas; CobM: cobertura de mineração; CobA: cobertura de agricultura; CobP: cobertura de pastagem; Dp: densidade populacional; DistAM: distância de áreas mineradas; DistV.JB: distância de viveiros e jardins botânicos.

Em seguida, com o intuito de evitar a multicolineariedade e correlação entre as variáveis preditoras no modelo global, foram adotadas executados os seguintes testes estatísticos: a correlação de Spearman $(<70 \%)$ (SPEAR et al. 2013) e VIF (Generalized Variance Inflation Factor <5) (VICENTE et al. 2014). Todas as variáveis que atenderam os requisitos foram incluídas no modelo.

Após a análise exploratória dos dados, verificouse que os dados apresentavam superdipersão e excessos de zeros, e por isso, os modelos lineares generalizados (GLM) foram ajustados à família não linear da distribuição Binomial Negativa (BOLKER 2007).

A partir do modelo global, efetuou-se a seleção dos modelos, respeitando o critério de menor AICc e $\triangle \mathrm{AICc}$ inferior a 2 (BURNHAM e ANDERSON, 2004). No entanto, não foram obtidos modelos parcimoniosos, ou seja, modelos com valor de peso Akaike $\left(\mathrm{w}_{\mathrm{i}}\right) \quad$ superior 0.9 (BURNHAM e ANDERSON, 2004). Assim, adotou-se a inferência multi-modelo a fim de garantir que apenas os melhores modelos fossem selecionados, incluindo todos até atingir o somatório de pesos Akaike igual 0.95. Como resultado dessa análise, obtém-se o modelo médio (model-average), uma função que modela a média e determina a magnitude e direção do impacto de cada variável preditora fundamentado nos melhores modelos a um intervalo de confiança de 95\% (BURNHAM e ANDERSON, 2004). Por fim, os efeitos das variáveis explicativas sobre a riqueza de EEI da flora terrestre considera o erropadrão (estimado e incondicional) para se estimar a 
importância relativa de cada variável independente. (BURNHAM, 2004; GRUEBER et al., 2011).

\section{RESULTADOS}

Da inferência multi-modelo, obteve-se o modelo médio a partir dos melhores seis modelos. A partir desse ranking, foi possível observar que o melhor modelo apresentou $\mathrm{w}_{\mathrm{i}}$ igual a 0.119 . Na Tabela 1 , é possível observar que as variáveis que apresentam importância relativa para a riqueza da flora em UC federais e são estatisticamente significativas foram: distância de áreas mineradas $\left(\Sigma \mathrm{W}_{\mathrm{i}}=1.0\right)$ e cobertura de floresta $\left(\sum \mathrm{w}_{\mathrm{i}}=0.5211\right)$. As demais variáveis, baseando-se em seus coeficientes médios, remetem incerteza com relação a variável resposta, sendo, portanto, consideradas sem efeito sob a riqueza de Tabela 1. Fatores que explicita a riqueza de EEIs da flora terrestre em 283 Unidades de Conservação federais brasileiras.

\begin{tabular}{|c|c|c|c|c|}
\hline Variáveis preditoras & Coeficientes & Erro-padrão & $\Sigma w i$ & valor $\mathbf{p}$ \\
\hline Intercepto & 1.1552 & 0.3169 & 0.0000 & 0.0003 \\
\hline Distância de áreas mineradas & -0.0095 & 0.0053 & 1.0000 & 0.0004 \\
\hline Cobertura de agricultura & 0.0277 & 0.0356 & 1.0000 & 0.1283 \\
\hline Cobertura de floresta & -0.0179 & 0.0150 & 0.5211 & 0.0193 \\
\hline Densidade populacional & 0.0012 & 0.0021 & 0.2670 & 0.2783 \\
\hline Cobertura de pastagem & 0.0135 & 0.0236 & 0.2632 & 0.2600 \\
\hline
\end{tabular}

Os coeficientes, erro padrão, soma de pesos Akaike ( $\Sigma$ wi) e valor p das variáveis preditoras foram decorrentes da análise de inferência multi-modelo

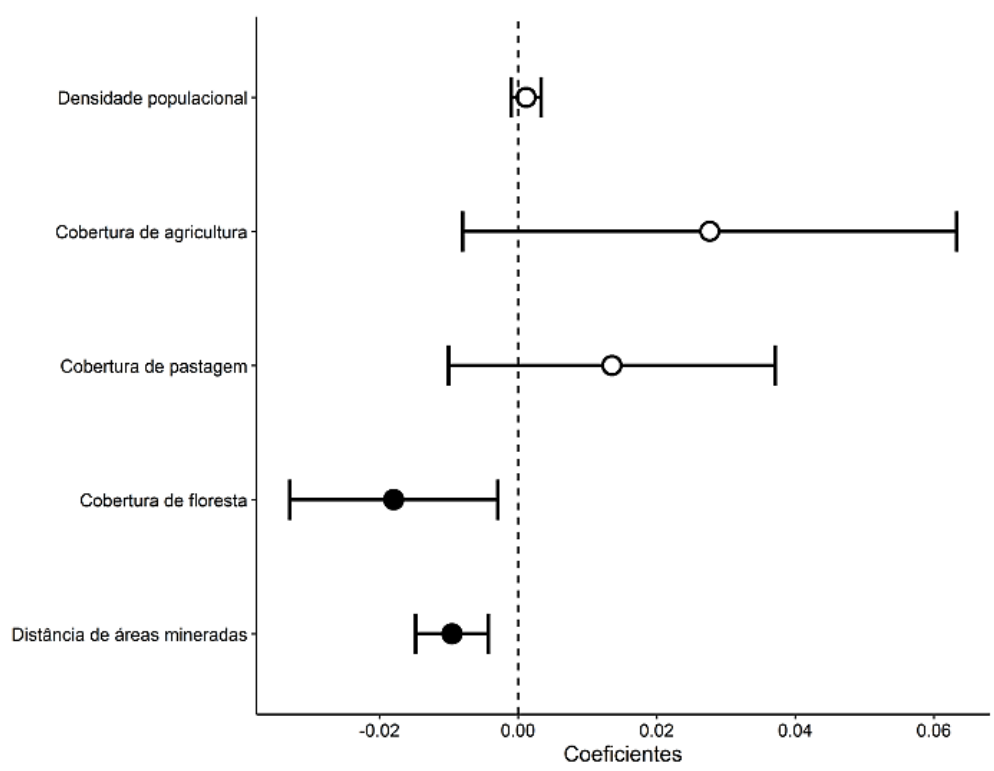

Figura 1 - Coeficientes das variáveis utilizadas no modelo. As variáveis significativas estão representadas com o círculo preenchido.

\section{DISCUSSÃO}

Dentre as oito variáveis estudadas, duas se mostraram estatisticamente significativas para a riqueza de espécies exóticas invasoras da flora terrestre nas Unidades de Conservação, sendo elas: distância de áreas mineradas e cobertura de floresta. Assim como há espécies com maior potencial de invasão, há também áreas que apresentam uma maior susceptibilidade a serem invadidas.

A invasibilidade de um local (ou ambiente) está relacionada com a capacidade que a espécie invasora tem de se adaptar às condições específicas do local. Ambientes fragmentados, ou seja, que espécies deste estudo e não inclusos no melhor modelo.

Na Figura 1, é possível observar as magnitudes do efeito de cada variável estatisticamente significativa para a inferência multi-modelo. Isto é, com o aumento da cobertura de floresta nativa, há a redução da riqueza de EEI da flora terrestre. Em contrapartida, a proximidade de áreas mineradas às UC promove o aumento dessa riqueza.

\begin{tabular}{|c|c|c|c|}
\hline entes & Erro-padrão & Ewi & valor $p$ \\
\hline 52 & 0.3169 & 0.0000 & 0.0003 \\
\hline 95 & 0.0053 & 1.0000 & 0.0004 \\
\hline 77 & 0.0356 & 1.0000 & 0.1283 \\
\hline 79 & 0.0150 & 0.5211 & 0.0193 \\
\hline 12 & 0.0021 & 0.2670 & 0.2783 \\
\hline 35 & 0.0236 & 0.2632 & 0.2600 \\
\hline
\end{tabular}


comportam no seu habitat natural (MAGALHÃES e SILVA-FORSBERG, 2016). O Brasil é detentor das reservas de nióbio $(98.02 \%)$, barita $(53.3 \%)$ e grafita natural $(50.7 \%)$, sendo estas consideradas as maiores reservas em relação ao restante do mundo. Além disso, os minérios de estanho, ferro e níquel também atuam de forma significativa nos valores de reserva mundial (OLIVEIRA, 2016). O fato de o Brasil conter grandes reservas de minério facilita a exploração e consequentemente o aumento de áreas degradadas. A mineração é considerada como uma das transformações mais agressivas de uso da terra devido ao grande impacto causado a biodiversidade e ao solo do local (LEMKE et al., 2013). A mineração acaba com a vegetação e com toda a comunidade de microrganismos e de fauna e flora que existem no local, favorece a compactação e acidificação do solo, reduz a absorção de água e o banco de sementes, ou seja, a mineração destrói o ecossistema e tem efeitos prolongados sobre o meio ambiente. As áreas degradadas são colonizadas por plantas invasoras, pois estas acabam sendo utilizadas na recuperação por serem pouco exigentes, apresentarem alta adaptabilidade às condições adversas e ao baixo teor de nutrientes, alta fixação de nitrogênio e possuírem rápido crescimento, tais características são desejáveis pelas empresas mineradoras, que buscam espécies de baixo custo e com bom desempenho para cobrir o solo exposto e combater a erosão (CALINGER et al., 2015; LEMKE et al., 2013).

A utilização de plantas invasoras na recuperação de áreas mineradas e em qualquer ambiente degradado, simboliza um grande problema, pois as invasoras impedem a sucessão de espécies nativas (LEMKE et al., 2013). A recuperação deve focar tanto no estabelecimento de plantas nativas, quanto em todos os processos que melhorem o solo e o deixem mais saudável, visto que dessa forma a invasão por plantas exóticas tenderá a diminuir (CALINGER et al., 2015). O Decreto-Lei n. 97.632/89 discorre sobre a obrigação do Plano de Recuperação de Áreas Degradas (PRAD) constar no Relatório de Impacto Ambiental (RIMA), seja este utilizado de uma forma preventiva ou corretiva em áreas degradadas por atividades mineradoras. Visando uma melhor aplicação da Lei, já que não há uma específica para cada estado brasileiro, é de suma importância que esta abranja também outras atividades que corroboram com o aumento de áreas degradadas (ALMEIDA, 2016), além de incentivar o plantio de espécies nativas com o intuito de favorecer a sucessão ecológica e aumentar a diversidade de espécies nessas áreas.

No Brasil, as Florestas Nacionais (FLONAs), categorizadas como UC de uso sustentável, vem sofrendo com atividades minerárias ilegais na
Amazônia, as quais são vedadas pelo SNUC (Sistema Nacional de Unidades de Conservação Lei 9985/2000) quando não autorizadas em planos de manejo. Uma vez autorizadas, as práticas minerárias geralmente ocorrem em lavras préexistentes, observando a data de criação da UC (SILVA, 2014). Nesse sentido, as práticas minerárias ilegais em FLONAs na Amazônia tem contribuído para o desmatamento e consequentemente aumentando a exposição desse tipo de UC a distúrbios antrópicos e introdução de espécies exóticas invasoras (FERREIRA et al. 2016).

Os serviços ecossistêmicos prestados pela cobertura florestal, como a amenização do clima, mitigação de carbono, conservação do solo, manutenção da fauna e da água, tem sido cada vez mais valorizados por melhorarem o bem-estar em ambientes urbanos e degradados (OLIVEIRA NETO et al., 2015), entretanto, tanto os ambientes florestais intocados quanto os fragmentos florestais que sofrem constantemente com às ações humanas, estão susceptíveis à invasão de plantas exóticas invasoras (MAGALHÃES e SILVA-FORSBERG, 2016). As invasões em cobertura florestal ocorrem de forma mais lenta, mas aumentam à medida que há interferências de processos antrópicos, como a propagação de patógenos e pragas, por exemplo. As florestas intocadas apresentam um atributo conhecido como resistência biótica, onde basicamente se refere a resistência das plantas nativas em relação a invasão de exóticas (MARTIN et al., 2009). Diversos estudiosos acreditam que a baixa riqueza e resistência às invasoras em coberturas florestais seja devido ao fato destas apresentarem um ecossistema mais equilibrado, com todos os seus recursos sendo utilizados de forma eficiente, não dando espaço para que outras espécies colonizadoras se estabeleçam (MAGALHÃES e SILVA-FORSBERG, 2016); sabe-se apenas que a invasibilidade está positivamente correlacionada com as perturbações antrópicas e que as florestas tropicais intocadas exibem baixa riqueza de espécies exóticas invasoras. Contudo, não há evidências suficientes para apoiar o fundamento de que as florestas tropicais são mais resistentes a invasão devido a sua alta diversidade. Até o momento sabese que as florestas tropicais, quando não sofrem ações do homem, apresentam pouca invasão por espécies exóticas, mas estudos que comprovem que é pela alta diversidade mantém-se sem base (FINE, 2002).

Espécies exóticas que são intolerantes à sombra não invadem florestas. Nesse caso, são as espécies exóticas tolerantes à sombra que ameaçam o ecossistema florestal. As florestas apresentam alta diversidade de espécies e boa distribuição dos seus 
recursos, mas não estão imunes ao ataque de invasores florestais. Diversos estudos têm indicado que as florestas tropicais e temperadas são susceptíveis a invasão de exóticas tolerantes à sombra. Martin et al. (2009) verificaram que 139 espécies de plantas exóticas invasoras foram consideradas tolerantes à sombra em seu estudo sobre a dinâmica de invasão em florestas de copa fechada. Para que essas espécies ocupem um ambiente florestal, não é necessário que este esteja perturbado ou sofrendo algum distúrbio, pois a maioria das espécies identificadas conseguem invadir sub-bosques de florestas altamente sombreados. Vale ressaltar que em Unidades de Conservação, onde há trilhas ou outras formas de passeio, as plantas invasoras utilizam desses meios para adentrarem nas florestas. Mesmo que os impactos provocados pelas plantas invasores tolerantes a sombra seja mais demorada na cobertura florestal do que em ecossistemas abertos, as consequências a longo prazo também são duradouras e preocupantes para a biodiversidade. Infelizmente o tempo de invasão mais lento das plantas exóticas favoreceu o descuido por parte dos órgãos ambientais, gerentes de UCs e demais pessoas que auxiliam no âmbito ambiental. Tal fato torna complicado o controle das EEIs e mais difícil a recuperação e manejo de áreas gravemente impactadas (MARTIN et al., 2009).

A baixa proporção de plantas exóticas invasoras, que apresentam sucessão tardia e são tolerantes à sombra, existentes em florestas sugere que este meio apresenta maior resistência a invasão do que aquelas florestas altamente perturbadas. Contudo, sabe-se que as plantas nativas também competem entre si pelos recursos disponíveis, mas em uma floresta, apenas as árvores mais altas e desenvolvidas são detentoras de um dos principais recursos, a luz. Portanto, para que uma invasão ocorra, é preciso que surjam pequenas aberturas no dossel provindas de transformações comuns nas florestas, como a própria dinâmica florestal. As brechas no dossel geralmente são pequenas, o que torna a dinâmica de invasão mais limitada, e esse fator mostra que espécies exóticas e nativas possivelmente são altamente tolerantes à sombra por conseguirem sobreviver a diversos ciclos de supressão antes mesmo do recrutamento do dossel. Em se tratando de florestas em ilhas tropicais, geralmente a introdução de plantas invasoras apresentam maior tolerância à sombra do que a maioria das nativas, o que propicia a invasão em ambientes intocados (MARTIN et al., 2009).

As florestas tropicais do mundo sofrem com as mudanças do ecossistema causadas, muitas vezes, pelas ações do homem. Áreas consideráveis de florestas tropicais são perdidas todos os anos para dar lugar aos cultivos agrícolas e pastagem, principalmente. Essas formas de uso da terra são extremamente agressivas por utilizaram maquinário pesado para a retirada da vegetação primária, utilizar diversos químicos no solo, e também utilizarem o fogo para a limpeza da área. Em áreas tropicais é muito raro a frequência de fogo, mas quando este ocorre, gera muitas consequências, como a eliminação da regeneração natural nativa e aumento da densidade de gramíneas, que em sua maioria são exóticas. Essas gramíneas são demasiadamente inflamáveis, o que favorece os incêndios que ocorrem anualmente. Além do mais, percebe-se que as espécies que têm mais sucesso na invasão são aquelas provindas de florestas plantadas ou são ornamentais, dando a entender que quando essas espécies são introduzidas em grande quantidade, elas conseguem realizar a invasão em vegetações vizinhas sem ajuda externa (FINE, 2002).

Apesar das demais variáveis (cobertura de agricultura, cobertura de pastagem, densidade populacional, distância de viveiros e jardins botânicos, cobertura de mineração e cobertura de florestas plantadas) não se mostrarem estatisticamente significativas na riqueza de EEI da flora terrestre nesse estudo, elas ainda são de demasiada importância no aumento de plantas invasoras nas Unidades de Conservação em todo o mundo. A alta densidade populacional, em especial, atua como uma excelente variável na disseminação de espécies exóticas invasoras em áreas protegidas, visto que a maior parte das introduções visam o bem-estar populacional. Entretanto, também visam o interesse econômico, sendo este último a grande motivação para continuar alimentando o mercado de exóticas invasoras. A falta de estudo da espécie e da área de interesse, principalmente, é um alerta para os pesquisadores, pois dessa forma é possível perceber que não há projetos de educação ambiental e políticas públicas suficientes para auxiliar a população no entendimento das exóticas invasoras (MAGALHÃES e SILVA-FORSBERG, 2016).

Além disso, a densidade populacional também influencia todas as demais variáveis, seja através do incentivo na utilização de plantas exóticas nos viveiros, pastagens, mineração e agricultura, ou através do descuido de turistas nas áreas protegidas e jardins botânicos, e descuido dos proprietários de terra, como é o caso das florestas plantadas que utilizam plantas exóticas (Pinus spp., Eucalyptus spp., Acacia spp., por exemplo) para fins de comercialização, mas estas acabam se dispersando para longe da propriedade.

Spear et al. (2013) observaram em seu estudo que a densidade populacional foi altamente significativa na riqueza de espécies exóticas nas áreas protegidas. As Unidades de Conservação que se encontram 
dentro de áreas urbanas ou próximas, tendem a sofrer com a maior pressão de propágulos de diferentes espécies, e a terem um maior impacto na biodiversidade. Unidades de Conservação são locais que apresentam uma alta riqueza de espécies nativas e que trazem vários benefícios socioeconômicos, e, portanto, devem ser protegidas. Medidas de mitigação, criação de zonas-tampão, monitoramento e vigilância dentro e ao longo do limite das UCs são algumas estratégias que podem ser adotadas. Buscar entender o que motiva as introduções, quais são as espécies de maior riqueza na área, detectar espécies ainda no início da invasão, entre outros fatores, é um dos métodos mais eficazes para prevenir a invasão em Unidades de Conservação, além de auxiliar na criação, aplicação e gestão de políticas públicas corretas (SPEAR et al., 2013).

\section{CONCLUSÃO}

Os resultados indicaram que Unidades de Conservação localizadas próximas às áreas antropizadas estão mais susceptíveis à invasão por plantas invasoras, especialmente aquelas próximas de áreas mineradas. $\mathrm{O}$ oposto acontece com a cobertura de florestas nativas, onde foi salientado que quanto maior a cobertura florestal nas UCs, menor seria a probabilidade de invasão. Deste modo, é importante que os tomadores de decisão busquem implementar políticas e ações, tomando em conta especialmente a distância de áreas mineradas, para reduzir os meios de propagação de espécies invasoras da flora em áreas protegidas no Brasil, além de promover a conservação dos remanescentes de vegetação natural no entorno das UCs. Tais medidas em longo prazo podem, em conjunto, reduzir a quantidade de EEI em UCs no Brasil. Ainda que a aplicação das leis tenha um custo relativamente alto, é primordial que os órgãos responsáveis implementem ações de controle e manejo para garantir a conservação das UCs no Brasil, a contemplar aquelas de melhor custobenefício como as estratégias para detecção precoce (ex.: sistemas de alerta que auxiliem na resposta rápida no manejo dessas $\mathrm{EEI})$.

\section{AGRADECIMENTOS}

Agradeço à Fundação de Apoio à Pesquisa do Distrito Federal (FAP-DF) pela bolsa concedida para a realização da pesquisa; ao Doutores Eraldo Matricardi e Rafaela Guimarães pela orientação e incentivo; aos servidores do Instituto Chico Mendes de Conservação da Biodiversidade (ICMBio) pela colaboração; e aos colegas de graduação do Departamento de Engenharia Florestal da Universidade de Brasília (EFL/UnB) pelos conhecimentos compartilhados ao longo do estudo.

\section{REFERÊNCIAS}

ALMEIDA, D.S. Legislação básica aplicada à recuperação ambiental. In: Recuperação ambiental da Mata Atlântica [online]. 3.ed. Ilhéus, BA: Editus, 2016, p. 32-39.

BOLKER, B. M. Ecological Models and Data in R. [s.1.] Princeton University Press, 2008, v. 25.

BURNHAM, K. P.; ANDERSON, D. R. Model Selection and Multimodel Inference. New York, NY: Springer New York, 2004. v. 172.

CAlinger, K., CALHOON, E., CHANG, H. C., WHITACRE, J., WENZEL, J., COMITA, L., and QUEENBOROUGH, S. (2015). Historic mining and agriculture as indicators of occurrence and abundance of widespread invasive plant species. PLoS ONE, 2015, v. 10 , p. $1-15$.

COLAUTTI, R.I., GRIGOROVICH, I.A. and MACISAAC, H.J. Propagule pressure: a null model for biological invasions. Biological Invasions, 2006, v.8, p. $1023-1037$.

FERREIRA, L. V., PAROLIN, P., MATOS, D. C. L., CUNHA, D. A., CHAVES, P. P., NECKEL, S. O. 2016. The effect of exotic grass Urochloa decumbens (Stapf) R.D.Webster (Poaceae) in the reduction of species richness and change of floristic composition of natural regeneration in the Floresta Nacional de Carajás, Brazil. Anais da Academia Brasileira de Ciências. v. 88(1 Suppl.): p. 589-597.

FINE, P. V. A. The invasibility of tropical forests by exotic plants. Journal of Tropical Ecology, 2002, v. 18, p. $687-705$.

GRUEBER, C.E., NAKAGAWA, S., LAWS, R.J. and JAMIELSON, I.G. Multimodelinference in ecology and evolution: challenges and solutions. Journal of Evolutionary Biology, 2011, v. 24, p. 699 -711.

LATOMBE, G., PYS ${ }^{\circ} E K, \quad$ P., JESCHKE, J.M., BLACKBURN, T.M., BACHER, S., CAPINHA, C.,COSTELlO, M.J., FERNÁNDEZ, M., GREGORY, R.D., HOBERN, D., HUI, C., JETZ, W., KUMSCHICK, S., MCGRANNACHAN, C., PERGL, J., ROY, H.E., SCALERA, R., SQUIRES, Z.E., WILSON, J.R.U., WINTER, M., GENOVESI, P. and MCGEOCH,M. A. A vision for global monitoring of biological invasions. Biological Conservation, 2017, v. 213, p. $295-308$.

LEMKE, D., SCHWEITZER C.J., TAZISONG, I.A., WANG, Y., BROWN J.A. Invasion of a mined landscape: what habitat characteristics are influencing the occurrence of invasive plants? International Journal of Mining, Reclamation and Environment, 2013, v. 27, p. $275-$ 293.

MAGALHÃES, L.C.S., SILVA-FORSBERG, M.C. Espécies Exóticas Invasoras: caracterização e ameaças 
aos ecossistemas. Scientia Amazonia, 2016, v. 5, n.1, p. 63-74.

MARTIN, P.H., CANHAM, C.D. and MARKS, P.L. Why forests appear resistant to exotic plant invasions: intentional introductions, stand dynamics, and the role of shade tolerance. Frontiers in Ecology and the Environment, 2009, v. 7, p. $142-149$.

MCDONALD, R.I., FORMAN, R.T.T., KAREIVA, P., NEUGARTEN, R., SALZER, D., FISHER, J. Urban effects, distance, and protected areas in an urbanizing world. Landscape and Urban Planning, 2009, v. 93, p. $63-75$.

OLIVEIRA, T.F. A influência do tratamento térmico em óxidos mistos de nióbio e tântalo nanoestruturados a partir da Columbita. 2016. 80f. Dissertação (Mestrado em Engenharia Química) - Universidade Federal do Rio Grande do Norte.

OLIVEIRA NETO, N.E., FONSECA, C.R., e CARVALHO, F.A. O problema das espécies arbóreas exóticas comercializadas nos viveiros florestais: Estudo de caso no município de Juiz de Fora (MG). Revista de Biologia Neotropical, 2015, v. 11, p. $28-46$.

PAUCHARD. A., ALABACK, P.B. Influence of elevation, land use, and landscape context on patterns of alien plant invasions along roadsides in protected areas of south-central Chile. Conservation Biology, 2004, v. 18, p. $238-48$.

PICKERING, C.M., MOUNT, A. Do tourists disperse weed seed? A global review of unintentional humanmediated terrestrial seed dispersal on clothing, vehicles and horses. Journal of Sustainable Tourism, 2010, v. 18 , p. $239-56$.

SAMPAIO, A. B. e SCHMIDT, I.B. Espécies exóticas invasoras em unidades de conservação federais do Brasil. Biodiversidade Brasileira, 2013, v. 3(2), p. 32 - 49.
SIGNORI, L.M. Mapeamento espaço temporal da exótica invasora Pinus spp. na área norte do Parque Nacional da Lagoa do Peixe. 2018. 87f. Dissertação (Mestrado em Sensoriamento Remoto) - Universidade Federal do Rio Grande do Sul. 2018.

SILVA, A.C. Mineração e unidades de conservação no Amapá: possibilidades e riscos. 2014. 48 f. Monografia (Bacharelado em Ciências Ambientais) - Universidade Federal do Amapá, Macapá, 2014.

SIMÕES, R.J.C.S. Plantas Invasoras no Jardim Botânico da Universidade de Coimbra: Contribuição para a Elaboração de um Plano Gestão. 2014. Dissertação (Mestrado em Ecologia) - Universidade de Coimbra. 2014

SPEAR, D., FOXCROFT, L. C., BEZUIDENHOUT, H. and MCGEOCH, M. A. Human population density explains alien species richness in protected areas. Biological Conservation, 2013, v. 159, p. $137-147$.

VICENTE, J., ALVES, P., RANDIN, C., GUISAN, A., HONRADO, J. What drives invasibility? A multi-model inference test and spatial modelling of alien plant species richness patterns in northern Portugal. Ecography, 2010, v. 33, p. 1081-1092.

VILA, M., and PUJADA, J. Land-use and socioeconomic correlates of plant invasions in European and North African countries. Biological Conservation, 2001, v. 100 , p. $397-401$. 